Case Report

\title{
Bilateral Paget's Disease of the Breast-Case Report of Long-Time Misdiagnosed Tumors with Underlying Ductal Carcinomas and Review of the Literature
}

\author{
Dietrich Barth \\ Hautarztpraxis Leipzig/Borna, Rudolf Virchow Straße, Borna, 04552 Leipzig, Germany \\ Correspondence should be addressed to Dietrich Barth; barthri@hotmail.com
}

Received 7 December 2013; Accepted 16 January 2014; Published 3 March 2014

Academic Editors: M. Jinnin and J.-H. Lee

Copyright (C) 2014 Dietrich Barth. This is an open access article distributed under the Creative Commons Attribution License, which permits unrestricted use, distribution, and reproduction in any medium, provided the original work is properly cited.

Paget's disease of the breast is often misdiagnosed. We report on a 72-year old patient with a history of 2.5 years without any malignant findings, followed by the identification of a bilateral Paget's disease with bilateral breast cancers. This case underlines how important histological examinations even in unusual clinical pictures are.

\section{Introduction}

Paget's disease $(\mathrm{PD})$ of the breast can be a diagnostic challenge. It might take years until the diagnosis. If the skin changes are intended to be benign but do not respond to topical therapy, a biopsy has to be performed to exclude malignancies. Almost all cases are single sided. We observed one of the rare cases of bilateral PD.

\section{A Case Report}

A 72-year-old woman (para 1) was seen with erythematous and eczematous patches that developed simultaneously on both nipples and had been present for 2.5 years (Figures 1(a) and $1(\mathrm{~d})$ ). No individual or familiar risk factors were known. She was extensively evaluated by gynecology and several investigations were performed (mammography, vacuumpunch biopsies, and cytological examination of breast fluid), but only minor dysplastic changes were detected in the breast fluid cytology. The patient was then treated with topical antimycotics, antibiotics, and corticosteroids.

After 2.5 years she was referred to dermatology, where we biopsied both nipples. The histopathology showed epidermal cells with hyperchromatic and polymorphic nuclei, intraepithelial gland cells (Figure 1(b)), and a high expression of cytokeratin 7 (Figure 1(c)), so-called Paget's cells. Cytokeratin 7 is a typical marker for glandular and transitional epithelia.

Because of an induration of the left mamma and the incidence of underlying carcinomas, the patient was evaluated again by gynecologists who decided to operate on both breasts. They identified a bifocal invasive ductal carcinoma and an intermediate grade ductal carcinoma in situ (DCIS) of the left breast and a low-grade DCIS of the right central breast. Sentinel lymph nodes were not involved. Following surgery, the patient received chemotherapy with 6 cycles FEC (5-fluorouracil, epirubicin, and cyclophosphamide), trastuzumab, because of positive Her-2 status, radiotherapy, and tamoxifen. At 1.5-year follow-up being maintained on tamoxifen, she showed no relapse.

\section{Discussion}

Between 1 and $4 \%$ of all breast cancers are Paget's diseases [1]. Bilateral synchronous tumors occur in about $1 \%$ of all breast cancers [2]. So far there are less than 10 reported women with synchronous bilateral PD. The age of these patients ranges from 45 to 74 years $[3,4]$. This phenomenon has been described twice in men $[5,6]$.

The disease appears in three forms: (1) associated with an underlying ductal carcinoma in situ (DCIS), (2) associated 


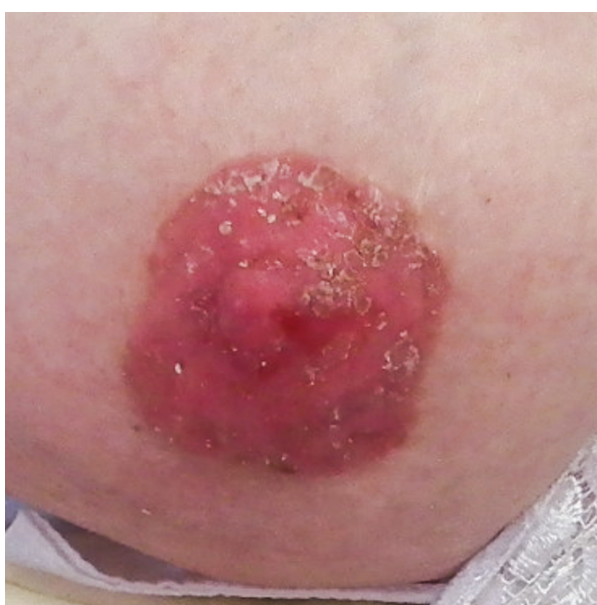

(a)

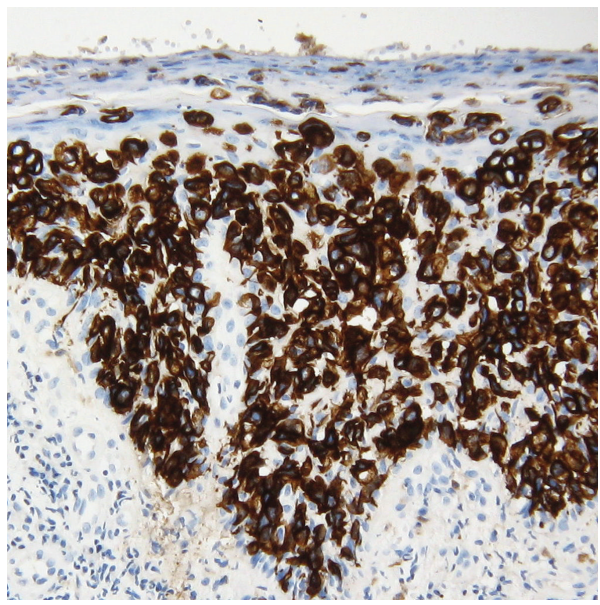

(c)

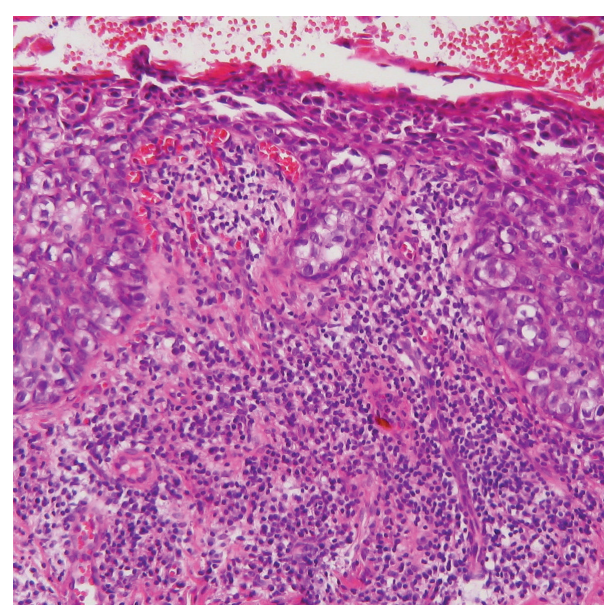

(b)

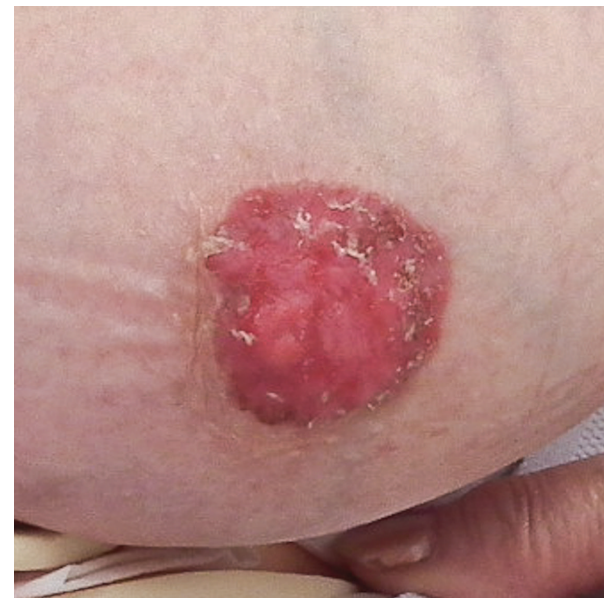

(d)

Figure 1: Clinical picture at time of first presentation and histological stains ((a) right breast, (b) cytokeratin 7 stain, (c) HE stain, and (d) left breast).

with an invasive carcinoma, or (3) without any underlying malignancy [7]. The majority of patients with PD have an underlying DCIS or even invasive carcinoma $[8,9]$.

For bilateral PD the limited data are controversial. Sahoo et al. [4] connected the PD of its patient to an underlying lobular CIS because of the immunohistochemical profile; Xie et al. [10] found no underlying tumor, whereas the patients of Anderson [11] and Franceschini et al. [12] as well as our patient had underlying ductal carcinomas.

It is still in discussion if the disease is the cause or consequence of an underlying malignancy. Most authors support the epidermotropism of malignant ductal gland cells into the epidermis. Some favor the migration of malignant keratinocytes from epidermis into deeper tissues, because in up to $50 \%$ of the cases no underlying tumors can be found [13].

Multiparous patients seem to have a reduced risk of ductal, lobular, tubular, and mucinous breast cancers. By contrast, the risk of medullary breast cancers increases with the number of pregnancies [14]. If similar findings for PD are evident [15] should be subject for further investigations. One explanation could be the inflammatory processes and restructuring of the ductal network after lactation [16].

The cause for the bilateral form of $\mathrm{PD}$ remains uncertain as the number of patients is limited and the reported patients differ in age, gender, and ethnicity (see Table 1). Coincidences cannot be excluded.

The treatment options are mastectomy or breastconserving strategies including nipple excision or central lumpectomy with a lymph node biopsy. There are reports of positive lymph nodes even without any underlying malignancies $[8,9]$. If surgery is not possible, radiotherapy, laser therapy, photodynamic therapy, or chemotherapy, for example, with trastuzumab or imiquimod, can offer a therapeutic alternative.

Although radiological diagnostic tools have improved over the years, each suspicious skin lesion of the breast must be biopsied in order to avoid the progression of a malignancy. Our patient's history of 2.5 years without any findings underlines the importance of early histological examinations. 
TABLE 1: Summary of all available cases of bilateral Paget's disease.

\begin{tabular}{|c|c|c|c|}
\hline Age/gender & Associated cancer & Country & Author/reference \\
\hline 53/female & L: intraductal carcinoma & USA & Anderson 1979/[11] \\
\hline Female & $?$ & Netherlands & Knol and Voorhuis 1981/[17] \\
\hline Female & ? & India & Sinha and Prasad 1983/[18] \\
\hline Male & ? & India & Nagar 1983/[5] \\
\hline 74/female & ? & Portugal & Fernandes et al. 1990/[3] \\
\hline Female & $?$ & Greece & Markopoulos et al. 1997/[19] \\
\hline $53 /$ female & $\begin{array}{l}\text { R: LCIS of the nipple, DCIS + microinvasive ductal } \\
\text { carcinoma } \\
\text { L: LCIS of the nipple, DCIS }\end{array}$ & USA & Sahoo et al. 2002/[4] \\
\hline $73 /$ female & $\begin{array}{l}\text { R: high-grade intraductal carcinoma } \\
\text { L: micropapillary invasive carcinoma }\end{array}$ & Italy & Franceschini et al. 2005/[12] \\
\hline $74 /$ male & R: infiltrative ductal carcinoma & Turkey & Ucar et al. 2008/[6] \\
\hline $45 /$ female & None & China & Xie et al. 2012/[10] \\
\hline $72 /$ female & $\begin{array}{l}\text { R: low-grade DCIS } \\
\text { L-intermediate DCIS, invasive ductal carcinoma }\end{array}$ & Germany & Barth 2014 \\
\hline
\end{tabular}

L: left breast; R: right breast; DCIS: ductal carcinoma in situ; LCIS: lobular carcinoma in situ.

\section{Conflict of Interests}

The author declares that there is no conflict of interests regarding the publication of this paper.

\section{References}

[1] J. K. Marshall, K. A. Griffith, B. G. Haffty et al., "Conservative management of Paget disease of the breast with radiotherapy: 10- and 15-year results," Cancer, vol. 97, no. 9, pp. 2142-2149, 2003.

[2] Y. X. Shi, Q. Xia, R. J. Peng et al., "Comparison of clinicopathological characteristics and prognoses between bilateral and unilateral breast cancer," Journal of Cancer Research and Clinical Oncology, vol. 138, no. 4, pp. 705-714, 2012.

[3] F. J. Fernandes, M. M. Costa, and M. Bernardo, "Rarities in breast pathology. Bilateral Paget's disease of the breast-a case report," European Journal of Surgical Oncology, vol. 16, no. 2, pp. $172-174,1990$.

[4] S. Sahoo, I. Green, and P. P. Rosen, "Bilateral Paget disease of the nipple associated with lobular carcinoma in situ: application of immunohistochemistry to a rare finding," Archives of Pathology \& Laboratory Medicine, vol. 126, no. 1, pp. 90-92, 2002.

[5] R. C. Nagar, "Bilateral Paget's disease of the nipple in a male," Journal of the Indian Medical Association, vol. 81, no. 3-4, pp. 55-56, 1983.

[6] A. E. Ucar, B. Korukluoglu, E. Ergul, R. Aydin, and A. Kusdemir, "Bilateral Paget disease of the male nipple: first report," Breast, vol. 17, no. 3, pp. 317-318, 2008.

[7] C.-Y. Chen, L.-M. Sun, and B. O. Anderson, "Paget disease of the breast: changing patterns of incidence, clinical presentation, and treatment in the U.S," Cancer, vol. 107, no. 7, pp. 1448-1458, 2006.

[8] M. Caliskan, G. Gatti, I. Sosnovskikh et al., "Paget's disease of the breast: the experience of the European institute of oncology and review of the literature," Breast Cancer Research and Treatment, vol. 112, no. 3, pp. 513-521, 2008.

[9] E. Siponen, K. Hukkinen, P. Heikkil, H. Joensuu, and M. Leidenius, "Surgical treatment in Paget's disease of the breast,"
The American Journal of Surgery, vol. 200, no. 2, pp. 241-246, 2010.

[10] B. Xie, H. Zheng, H. Lan, B. Cui, K. Jin, and F. Cao, "Synchronous bilateral Paget's disease of the breast: a case report," Oncology letters, vol. 4, no. 1, pp. 83-85, 2012.

[11] W. R. Anderson, "Bilateral Paget's disease of the nipple: case report," American Journal of Obstetrics \& Gynecology, vol. 134, no. 8, pp. 877-878, 1979.

[12] G. Franceschini, R. Masetti, D. D’Ugo et al., "Synchronous bilateral Paget's disease of the nipple associated with bilateral breast carcinoma," The Breast Journal, vol. 11, no. 5, pp. 355-356, 2005.

[13] G. H. Sakorafas, K. Blanchard, M. G. Sarr, and D. R. Farley, "Paget's disease of the breast," Cancer Treatment Reviews, vol. 27, no. 1, pp. 9-18, 2001.

[14] G. K. Reeves, K. Pirie, J. Green, D. Bull, and V. Beral, "Reproductive factors and specific histological types of breast cancer: prospective study and meta-analysis," British Journal of Cancer, vol. 100, no. 3, pp. 538-544, 2009.

[15] G. Albrektsen, I. Heuch, and S. Ø. Thoresen, "Histological type and grade of breast cancer tumors by parity, age at birth, and time since birth: a register-based study in Norway," BMC Cancer, vol. 10, article 226, 2010.

[16] P. Schedin, J. O’Brien, M. Rudolph, T. Stein, and V. Borges, "Microenvironment of the involuting mammary gland mediates mammary cancer progression," Journal of Mammary Gland Biology and Neoplasia, vol. 12, no. 1, pp. 71-82, 2007.

[17] W. L. R. Knol and F. J. Voorhuis, "Paget's disease of the breast: a case of bilateral occurrence," Nederlands Tijdschrift voor Geneeskunde, vol. 125, no. 11, pp. 416-418, 1981.

[18] M. R. Sinha and S. B. Prasad, "Bilateral Paget's disease of the nipple," Journal of the Indian Medical Association, vol. 80, no. 2, pp. 27-28, 1983.

[19] C. Markopoulos, H. Gogas, F. Sampalis, and B. Kyriakou, "Bilateral Paget's disease of the breast," European Journal of Gynaecological Oncology, vol. 18, no. 6, pp. 495-496, 1997. 


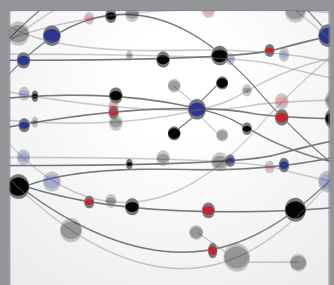

The Scientific World Journal
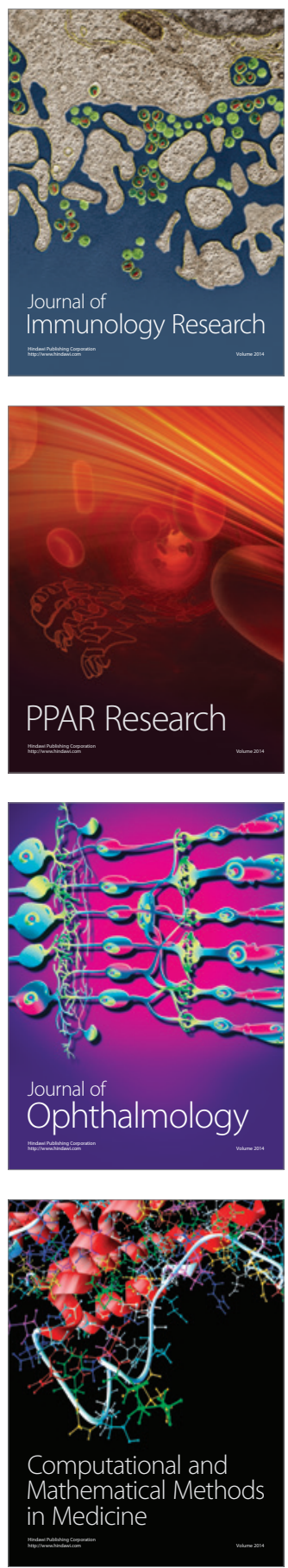

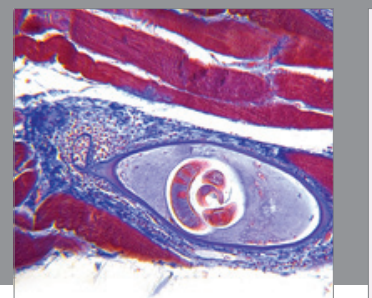

Gastroenterology

Research and Practice
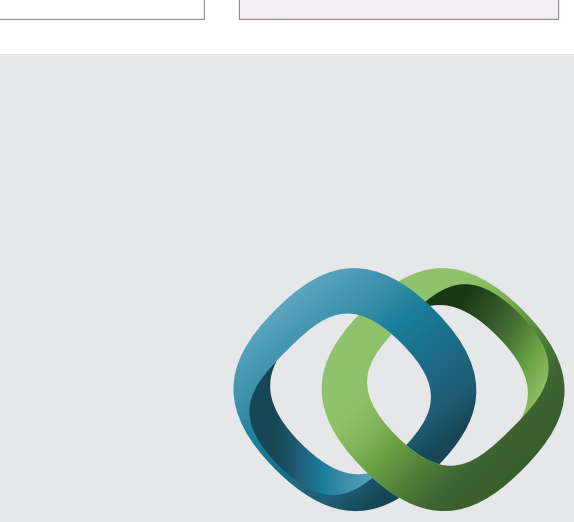

\section{Hindawi}

Submit your manuscripts at

http://www.hindawi.com
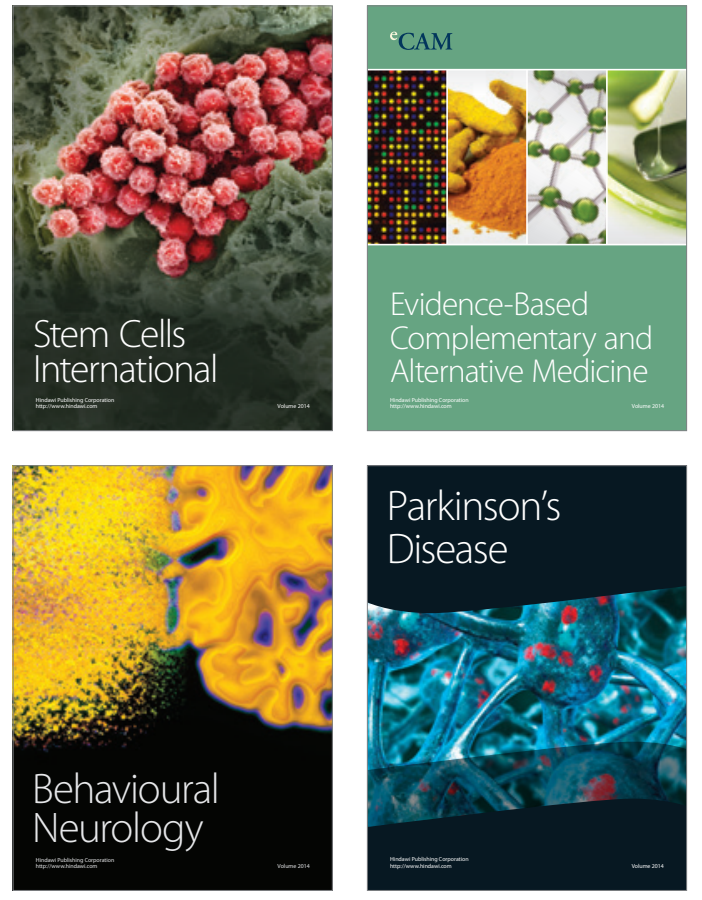
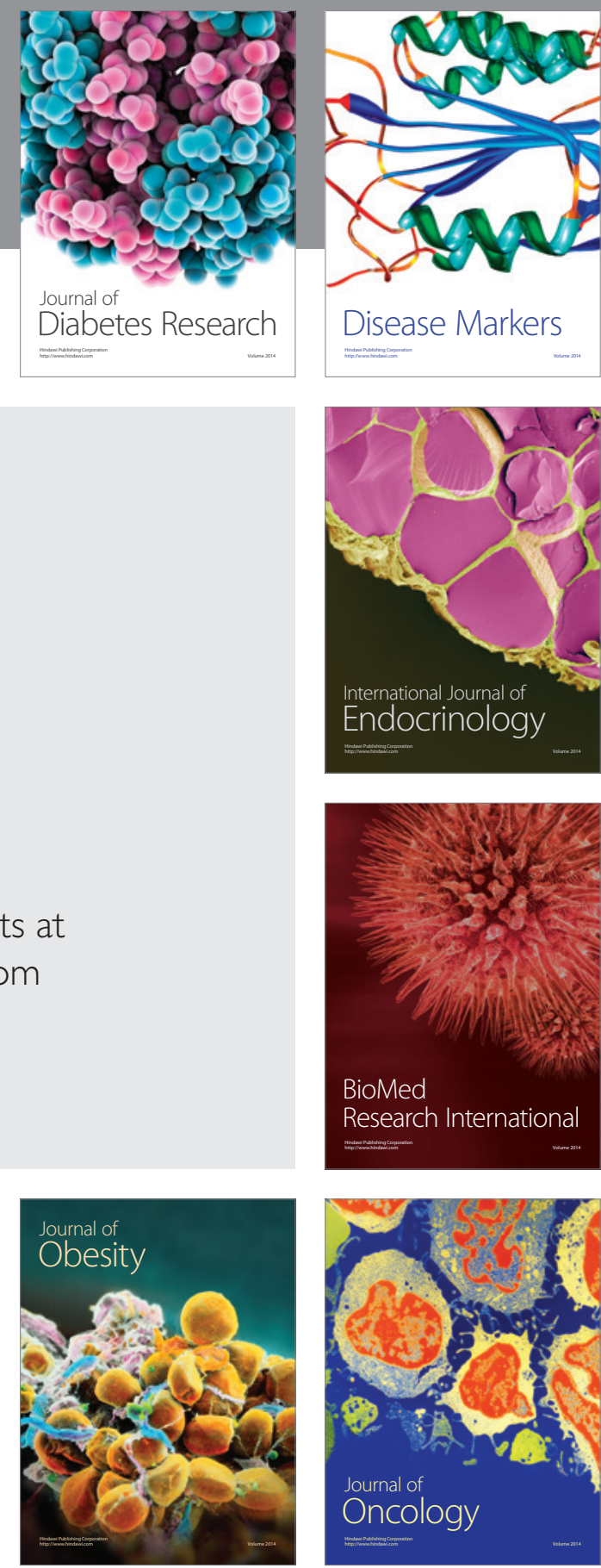

Disease Markers
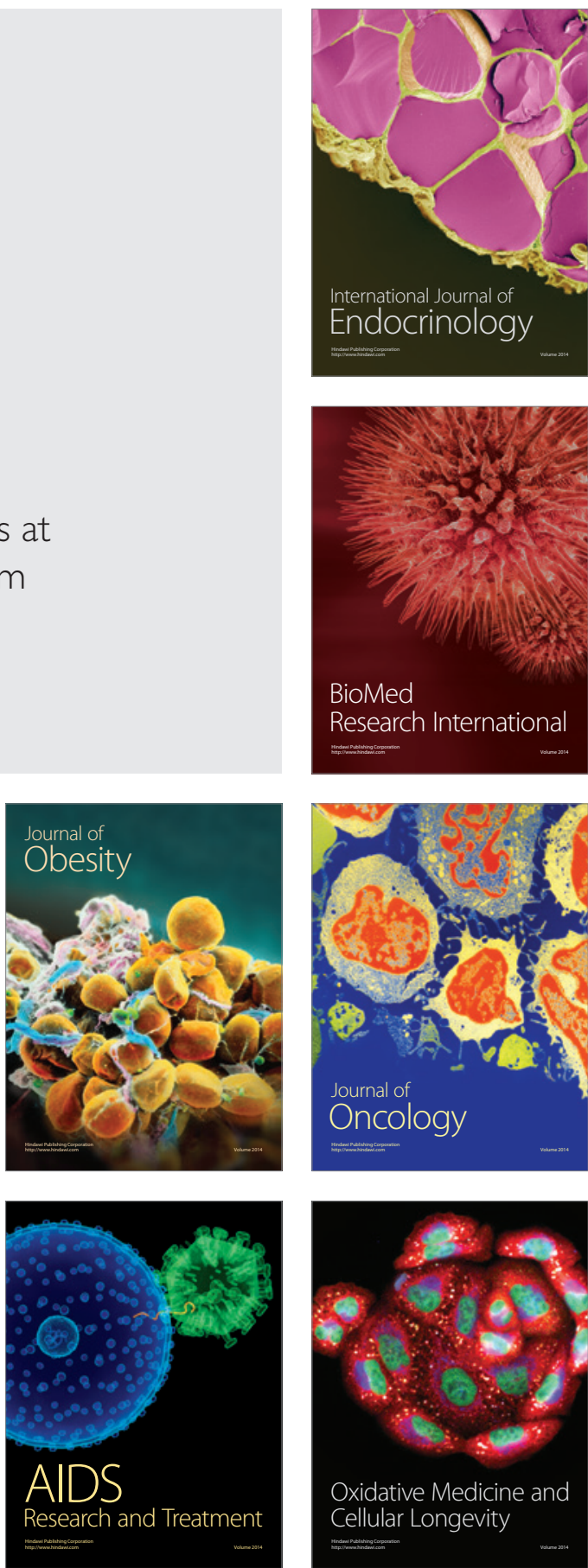